\title{
Implementing Strategies at the Workplace Level to Increase Colorectal Cancer Screening Uptake in Public Workers in Argentina: A Controlled Interrupted Time Series Study.
}

Ariel Esteban Bardach ( $\nabla$ abardach@iecs.org.ar )

Consejo Nacional de Investigaciones Científicas y Técnicas https://orcid.org/0000-0003-4437-0073

Andres Pichón-Riviere

IECS: Instituto de Efectividad Clinica y Sanitaria

Luz Gibbons

IECS: Instituto de Efectividad Clinica y Sanitaria

Juan Pedro Alonso

IECS: Instituto de Efectividad Clinica y Sanitaria

Sacha Alexis Virgilio

IECS: Instituto de Efectividad Clinica y Sanitaria

María Belizán

IECS: Instituto de Efectividad Clinica y Sanitaria

Mariana Comolli

IECS: Instituto de Efectividad Clinica y Sanitaria

Lucas Angel Damián González

IECS: Instituto de Efectividad Clinica y Sanitaria

Research

Keywords: Screening, Colorectal Cancer, Argentina, Implementation, Workplace

Posted Date: January 15th, 2021

DOl: https://doi.org/10.21203/rs.3.rs-146130/v1

License: (9) (7) This work is licensed under a Creative Commons Attribution 4.0 International License. Read Full License 


\section{Abstract}

Background

Colorectal cancer (CRC) is the third most common neoplasm and the fourth cause of cancer death worldwide. In Argentina, more than 16,000 cases are diagnosed and 8,700 people die each year. The Immunochemical Faecal Occult Blood Test (iFOBT) is recommended for the prevention and early detection of $\mathrm{CRC}$ in people of both sexes, between 50 and 75 years old with average-risk. The worksite setting has great potential to improve adherence to preventive interventions. We aimed to design and evaluate the feasibility, acceptability, and effectiveness of a strategy implemented in the workplace to improve the rate of adherence to the IFOBT screening in employees of the government's Revenue Agency of the Province of Buenos Aires (ARBA).

Methods

We used a quasi-experimental research design, a controlled interrupted time-series (ITS). The study period was divided into two-time segments: (1) a 51month pre-intervention period (July 2015 through September 2018); (2) a 5-month post-intervention period (October 2018 through February 2019 ). We performed an initial formative research using qualitative research methods (semi-structured interviews, focus groups) in order to inform the design of the intervention and adapt it, to ensure that it is both feasible and implementable by the target population. We fitted segmented linear regression models to evaluate changes in the monthly rates per 10,000 of tests done in ARBA employees, and controlling for the proportion of tests done in non-ARBA workers.

Results

A total of 1552 ARBA employees aged 50 or more participated. Overall, iFOBT mean uptake rates were 16 times higher in the intervened during the five-month intervention period, remaining statistically significant after adjusting by the proportion of tests done in the control group ( $p<0.001)$. This observed effect was higher in women aged 50 to 59 years. Activities were suspended due to the Covid-19 pandemic lockdown in the country in 2020.

Conclusions

A multifaceted workplace-based intervention helped increase the uptake of CRC screening in public sector employees of the province of Buenos Aires, Argentina. Achieving high implementation rates requires building a healthy relationship with the partner organization, adding their values and views, and establishing agreed upon mechanisms and realistic timelines.

\section{Contributions To The Literature}

- The formative research with qualitative methods helped designing the appropriate interventions, under the Consolidated Framework for Implementation Research (CFIR), which included information brochures, advertisement in partners' intranet, social network posts, emailing, sensitizing lectures and videointerviews and mini-group workshops.

- Employee-facing multifaceted worksite cancer screening interventions are a valuable means to increase knowledge and utilization of workers, and constitute a valuable implementation tool when appropriately tailored to its target population.

- Overall, the controlled ITS showed that CRC screening mean uptake rates were 16 times higher in the intervened versus the control population during the intervention period, particularly among women aged 50-75.

\section{Background}

Colorectal cancer (CRC) is the third most common neoplasm and the fourth cause of cancer death worldwide. During 2020, 1.93 million new cases were diagnosed and 935,000 deaths from CRC were estimated.(1) Argentina is among the countries with the highest incidence and mortality rates for CRC in South America (it is only surpassed by Uruguay). Approximately each year more than 16,000 cases are diagnosed and 8,700 people die, which corresponds to an incidence and mortality rate of 25 and 12.6 per 100,000 inhabitants. In this way, it constitutes the second cause of specific mortality in Argentina after lung cancer. Most cases are sporadic (75\%) and affect those over 50 years of age (90\%).(1)

The long latency of CRC transformation turns it into a preventable tumour, to the extent that its precursor lesion, the adenomatous polyp, is a slow growing lesion. Only $5 \%$ of these lesions will progress to invasive carcinoma after a mean time of 10 years, which makes it possible to interfere and modify their natural history.(2) The transition from the polyp to carcinoma is $90 \%$ related to age (over 50 years) in both sexes, which represents a primary factor in analysing disease control strategies in the coming years. This provides some time for the screening to take place.

The Immunochemical Faecal Occult Blood Test (iFOBT) is a test that examines the possible presence of blood in the stool, which can be a sign of cancer or polyps.(2)

The performance of the test annually in people between 50 and 75 years of age has shown to reduce mortality from CRC and to be a cost-effective screening strategy in Argentina.(3)

In Argentina, the National Cancer Institute (INC) has started the implementation of a National Program for the prevention and early detection of CRC with iFOBT annually in people of both sexes, between 50 and 75 years old, without a personal or family history of colorectal disease. For a screening program to be effective, coverage of at least $70 \%$ of the population is required. The fourth edition of the National Survey of Risk Factors(4) conducted in 2018 enquired about the CRC screening in the interviewed population. A total of 29,224 people was interviewed, of which 10,102 were between 50 and 75 years of age, representing $34.5 \%$ of the total survey participants. Of those, $57.1 \%$ were women $(n=5,766)$, with the mean age for both sexes being 61 years. The response rate for this

Page $2 / 10$ 
section of the survey was only $28.5 \%(n=2,883)$. Of these, $12 \%(n=347)$ had undergone IFOBT in the last year, while $57.4 \%(n=1,653)$ had a colonoscopy done in the last five years.

The adherence rate of the general population to screening is low. Multiple factors explain this, with low public knowledge being one of the main reasons.

The workplace setting has great potential to improve adherence to preventive interventions, becoming increasingly recognised for disseminating information and implementing health promotion activities, including those aimed at the prevention and early detection of cancer.(5-8) It represents a convenient environment for behavioural changes and prevention, particularly due to the fact that many neoplasms are closely related to lifestyle. In addition, it allows targeting a captive population, thus reaching even those who do not regularly visit the doctor, or request a periodic health examination. The benefits of implementing programs in the workplace include improving the health of employees but also increasing their levels of productivity.

Several methodologies have been implemented. Employee-facing strategies as electronic invitation and reminders seem to positively influence the percentage of participation and early detection in CRC in a given setting. $(9,10)$ Telephone calls, intranet messages and videos, flyers, the use of social networks, e-mail or the mobile messaging system of mobile phones, letters of invitation, sending of educational material, provision of a kit to carry out the test at home, or combinations of these have been shown to be more effective than non-intervention in increasing the percentage of adherence. A better uptake of screening may lead to future high health benefits and cost reductions both for the employer and the health system.

As a pilot project based on the guide developed for the implementation of programs for the prevention and early detection of CRC from the INC(11), it has the potential to be scalable to the entire province of Buenos Aires, or to other provincial or national government and non-government institutions.

The objective of this study was design and evaluate the feasibility, acceptability, and effectiveness of a strategy implemented in the workplace to improve the rate of adherence to the IFOBT screening in workers of the Internal Revenue Agency of the Province of Buenos Aires (ARBA from its acronym in Spanish 'Agencia de Recaudación de Buenos Aires'), a public institution. Secondary objectives were to identify those factors hindering or facilitating adherence to the screening program.

\section{Methods}

Aim, study design and data sources

With the aim of implementing an intervention at the workplace level to increase colorectal cancer screening uptake in public workers in Argentina we used a quasi-experimental research design: a controlled interrupted time-series (ITS). The ITS assesses the frequency of the outcome measures multiple times before and after a timed intervention.(12) In our case, the study period was divided into two-time segments: (1) a 51- month pre-intervention period (July 2015 through September 2018); (2) a 5-month post-intervention period (October 2018 through February 2019).

Setting and participating institutions

ARBA is the Revenue Agency of the province of Buenos Aires. It is public body subordinated to the government of the Province of Buenos Aires. It had about 4,900 employees at the beginning of 2018, working throughout the Buenos Aires province in different branches (about 200 in 125 municipalities). The most populous are in the city of La Plata, which includes almost half of the personnel, followed by those operating in localities such as Buenos Aires City, Mar del Plata Avellaneda, Bahía Blanca, Morón, Junín, Azul, Lomas de Zamora Vicente López and Junín. Almost $60 \%$ in this age range are women. The institution had some previous experience in the implementation of health programs.

ARBA provided information on the total number of employees aged between 50-75 years during the study period affiliated to the main public employmentbased health maintenance organization (HMO) of the Province of Buenos Aires, called IOMA (from its acronym in Spanish: 'Instituto Obra Medico Asistencial'). All ARBA employees are health-insured by IOMA. The HMO in turn, provided an anonymized database from its colorectal cancer prevention program with the information of the employees that were tested, and background screening rates both in the ARBA and in the non-ARBA (control) population. The latter group is also composed by public employees of the Province of Buenos Aires, but from other dependencies. These two databases were merged. This prevention program has been in force since 2015. The Biochemical Federation of the Province of Buenos Aires (FABA) provided information and facilitated the process.

This implementation project counted with the endorsement of the Ministry of Health of the Province of Buenos Aires, through their Cancer Control Programme authorities and that of IOMA and FABA. Funding came from the Argentinean Cancer Institute. The study protocol was registered in the Argentina Registry of Health Research (RENIS) under the code IS002339.

A verbal informed consent for the interviews was obtained from participants and is shown in the Appendix (in Spanish). Weekly meetings with ARBA personnel ensured permanent communication, in all phases of the project. Additionally, more than 10 face-to-face visits to ARBA La Plata and one in IECS took place. Also, Vicente Lopez, Junín and Lomas de Zamora's ARBA staff were interviewed.

Intervention design

\section{First step: Initial rapid review of the effectiveness of workplace interventions}

With the objective to evaluate the available global evidence about the efficacy of different interventions in the workplace aimed at increasing CRC screening, a rapid health technology assessment (HTA) was undertaken (Gonzalez, LAD personal communication, available on demand). 
The multicomponent recommendations of the United States Centres for Disease Control and Prevention (CDC) for colorectal cancer screening were considered in the planning stage of the intervention. $(13,14)$

\section{Second step: Formative research}

In order to provide information for the design of the intervention to increase screening rates and adapt it to ensure that it is both feasible and implementable by the target population, a formative investigation was carried out, based on the triangulation of qualitative investigation techniques: semi-structured interviews with key informants and focus groups. The Consolidated Framework for Implementation Research (CFIR) approach was used.(15, 16) It describes a list of dimensions or constructs that have been shown to influence (either as barriers or facilitators) the health policy implementation processes, and provides a pragmatic organization of dimensions from which they can be described and / or understand the specific mechanisms that influence the outcome of the interventions.

The objective was identifying the characteristics and resources of the institution to consider for designing and implementing the intervention. These features include for example, the profile staff, the institutional culture, the communication channels already in place etc. In addition, we aimed to explore people's perceptions, beliefs and attitudes towards colorectal cancer and screening tests by the target population. After requesting informed consent, semi-structured interviews (personal and group) were conducted with key informants. The selection of the informants was agreed with ARBA authorities, by virtue of their potential influence on the design and implementation of the intervention.

\section{Outcomes}

Our unit of time measurement was one month. For each month, the eligible population was the total number of ARBA employees over 50-75 years who were not tested in the last year. We calculated the number of tests done per 10,000 ARBA employees in each month. In a subgroup analyses, we explored whether the effect of the intervention varied across different age groups in women and in men, and the influence of the summer season. We also calculated the number of tests done per 10,000 of non-ARBA IOMA affiliates employees aged 50-75 in each month. This series was used as a control series as this group did not receive the intervention

Statistical analyses

We fitted segmented linear regression models to evaluate changes in the monthly rates per 10,000 of tests done in ARBA employees. Segmented regression analysis is used to measure statistically the changes in level and slope in the post-intervention period compared to the pre-intervention period. In other words, segmented regression is used to measure immediate (level) changes in the rate of the outcome as well as changes in the trend (slope). We used this model to evaluate the impact of the intervention in the whole population and by age group in women and in men. Two different models were used in each analysis. The first model was the typically segmented linear regression in which we included the following indicators: (1) an intervention indicator variable ( 0 for the pre intervention period, 1 for the post-intervention period, representing the level change), (2) the month indicator ( 1 to 56 , representing the baseline trend), and ( 3 ) the post-intervention month indicator ( 0 in the 51 pre intervention months, 1 to 5 in post intervention months, representing the trend change). The second model aimed to evaluate the impact of the intervention after controlling for the number of tests done per 10,000 non-ARBA IOMA affiliates employees. In this model, we also included a group employee indicator ( 0 for IOMA and 1 ARBA, representing the difference in intercept) and interaction terms between this group employee indicator and the three above mentioned indicators. The three interactions terms represent the difference in the baseline trend, in the level change and in the trend change (see appendix Table A.1 for statistical equations). In an additional analysis, an indicator variable representing the summer season (January and February) in which employees do not usually services was included. We tested and accounted for clustering of observations across time (i.e., autocorrelation) by using the generalized Durbin-Watson test and included the appropriate autocorrelation orders in the final models. All analyses were conducted with $\mathrm{R}$ version 4.0.2.

\section{Results}

The initial HTA performed as part of the project found moderate-quality evidence suggesting that a complex intervention developed in the workplace could be useful to increase the CRC screening rate in people between 50 and 75 years of age. The screening programs identified in countries of the Americas mention faecal immunochemical tests as the desired initial diagnostic test; however, their coverage in most of the countries of this region was either unknown or less than $50 \%$.

To undertake the abovementioned formative research phase, a total of ten semi-structured interviews were administered to ARBA informants from different areas of the province of Buenos Aires. Also, eight focus groups with 53 employees aged 50 or more were held in four ARBA branches. (Alonso et al, personal communication, available on demand)

The intervention and its implementation

Using these inputs, the multifaceted, employee-facing interview consisted of several components: paper-based and digital information brochures (flyers), advertisements in ARBA Intranet about the launching of activities, e-mailing lists, active involvement of institution authorities, the presence of banners in the institution, social network posts (ARBA Facebook group and WhatsApp), a sensitizing institution-wide lecture and mini-group workshops in ARBA Headquarters. Audio-visual equipment and staff were facilitated by ARBA. Video interviews to employees and to the project's oncologist were done to raise employees' awareness in October 2019. Generic communication texts were also developed. Moreover, visual content already available from the National Cancer Institute and from IOMA were integrated in the flyers. These flyers were placed inside the iFOBT kits (see Appendix for picture). They were sent to ARBA's headquarters in November 2019, and then delivered to the branches in the Buenos Aires Province throughout the month of November. In addition, a digital version of the flyer was sent to all employees during the same month (see Appendix for content, photograph). 
Table 1 shows the characteristics of the 1552 ARBA employees aged 50 or more. Figure A1 in the Appendix shows the monthly number of total employees of this age group in 2015-2020. A slight predominance of the female gender was observed (56.8\%). The majority were younger than 60 years of age ( $86.1 \%$ ). Nearly half of the target population (49.9\%) worked in the city La Plata, in ARBA's central office. Table 2 shows the mean of the monthly rates of tests done per 10,000 people during the control and intervention period. The mean of the monthly rates was 8.4 per 10,000 employees in the control period and 130.5 in the intervention period. The impact of the intervention shows a significant effect both statistically and from the public health standpoint. Overall, IFOBT mean uptake rates were 16 times higher in the intervened versus the control population. The impact remains significant after adjusting by the number of tests done per 10,000 non-ARBA IOMA affiliates employees. The effect of the intervention was higher in women, particularly on those aged 50 to 59 years. Figure 1 shows the rates of $\mathrm{iFOBT}$ tests done per 10,000 employees, historically from the inception of the IOMA program, depicting a spike in the last trimester of 2019 and the two first months of 2020, when the intervention occurred. Figures 2 and 3 depict the uptake in women and men employees, respectively. More detailed results are shown in the Appendix: Table A.1 shows the parameters of the segmented linear regression model and their interpretation and Table A.2, the number and mean rates of monthly tests done per 10,000 by trimester from 2015 to 2020 . Table A.3 shows the level of change and trends in the monthly rates for the total target population by relevant age groups; Table A.4 the same in women and Table A.5 in men. Of note, no significant changes were found when adjusting for the influence of the summer season (Table A.3).

Table 1

Characteristics of ARBA employees

\begin{tabular}{|c|c|c|c|c|c|c|c|}
\hline & & \multicolumn{2}{|c|}{50 to 59 years } & \multicolumn{2}{|c|}{60 years or more } & \multicolumn{2}{|l|}{ Total } \\
\hline & & $n / N$ & $\%$ & $n / N$ & $\%$ & $n / N$ & $\%$ \\
\hline \multirow[t]{2}{*}{ Gender } & Female & $763 / 1336$ & 57.1 & $119 / 216$ & 55.1 & $882 / 1552$ & 56.8 \\
\hline & Male & $573 / 1336$ & 42.9 & $97 / 216$ & 44.9 & $670 / 1552$ & 43.2 \\
\hline \multirow[t]{2}{*}{ Jurisdiction } & ARBA Central & $666 / 1336$ & 49.9 & $100 / 216$ & 46.3 & $766 / 1552$ & 49.4 \\
\hline & Peripheral offices & $670 / 1336$ & 50.1 & $116 / 216$ & 53.7 & $786 / 1552$ & 50.6 \\
\hline Total & & $1336 / 1552$ & 86.1 & $220 / 1552$ & 14.2 & $1552 / 1552$ & 100.0 \\
\hline
\end{tabular}

Table 2 Impact of the intervention on monthly proportion of tests done, parameters from the segmented linear regression.

\begin{tabular}{|c|c|c|c|c|c|c|}
\hline & \multirow{2}{*}{$\begin{array}{l}\text { Control Period } \\
\text { Mean of the monthly } \\
\text { rates (S.D.)* }\end{array}$} & \multirow{2}{*}{$\begin{array}{l}\text { Intervention Period } \\
\text { Mean of the monthly } \\
\text { rates (S.D.)* }\end{array}$} & \multicolumn{2}{|c|}{$\begin{array}{l}\text { Impact of the intervention on } \\
\text { monthly rates }\end{array}$} & \multicolumn{2}{|c|}{$\begin{array}{l}\text { Adjusted Impact of the intervention on } \\
\text { monthly rates }\end{array}$} \\
\hline & & & Estimate $(95 \% \mathrm{Cl})$ & P-Value & Estimate $(95 \% \mathrm{Cl})$ & P-Value \\
\hline Overall & $8.4(8.3)$ & 130.55 (121.78) & $176.4(141.2 ; 211.6)$ & 0.0000 & $134.2(93.4 ; 174.9)$ & 0.0000 \\
\hline \multicolumn{7}{|l|}{ Women } \\
\hline $\begin{array}{l}50 \text { to } \\
59 \text { years }\end{array}$ & $8.5(12.8)$ & $195.4(188.6)$ & $265.8(215.5 ; 316.0)$ & 0.0000 & $249.0(193.1 ; 304.9)$ & 0.0000 \\
\hline $\begin{array}{l}60 \text { years or } \\
\text { more }\end{array}$ & $14.1(41.6)$ & $127.3(109.4)$ & $164.2(41.5 ; 286.8)$ & 0.0114 & $153.1(25.9 ; 280.2)$ & 0.0203 \\
\hline \multicolumn{7}{|l|}{ Men } \\
\hline $\begin{array}{l}50 \text { to } \\
59 \text { years }\end{array}$ & $8.0(13.7)$ & $66.6(65.1)$ & $101.0(71.1 ; 131.0)$ & 0.0000 & $84.7(51.6 ; 117.7)$ & 0.0000 \\
\hline $\begin{array}{l}60 \text { years or } \\
\text { more }\end{array}$ & $5.0(24.9)$ & $67.3(67.2)$ & $61.8(1.9 ; 121.8)$ & 0.0483 & $52.4(-9.9 ; 114.7)$ & 0.1025 \\
\hline
\end{tabular}

\section{Discussion}

Our interrupted time series showed an important effect of the intervention during the five months of its implementation, which was unfortunately halted by the Covid-19 pandemic.

The methodological approach utilized considered the population of interest to estimate the impact of a multifaceted intervention starting on September 2019, on screening uptake by comparing the average changes since 2015 and over the five months of the adoption of our intervention. To our knowledge this is the first experience to test and document the implementation of CRC screening-enhancing strategies in workplaces in Argentina.

O'Keefe et al, for example, provided free CRC screening to Alabama University to 146 employees and dependents, with high return rates, suggesting that employer-based screening initiatives are a systematic and replicable means of improving CRC screening.(7) McFall et al(17) reported in 2014 the experience of implementing a client reminder intervention for CRC screening at a health insurance worksite. Of 95 employees offered the test, $16 \%$ were effectively tested, increasing rates. Rafie et al(18) implemented in 2019 a worksite colon cancer awareness program to increase colorectal cancer screening rates and preventive 
lifestyle behaviors among its employees in Virginia, US. The program included information sessions covering the topics of colorectal cancer, screening guidelines, insurance coverage, and preventive lifestyle behaviors utilizing a web-based system for the information sessions, and resulted in broad participation, a significant increase in screening self-efficacy, changes in diet and physical activity, and a $20.6 \%$ increase in the employee colorectal cancer screening rate.

Increasing knowledge by means of sensitizing activities, interactive sessions and flyers is important in this disease. Powe et al(19) published in 2004 the results of an intervention study to increase screening among community elders in the US, and concluded that those with greater knowledge of colorectal cancer were more likely to participate. They used videos, posters and an educational calendar to educate. Also, in the US Warner et al(20) showed the results of a workplace-based Intervention to improve awareness, and utilization of CRC screening among 265 Latino labor employees in Utah, improving knowledge and adherence. Shih-Yung Su et al(21), published recently the results of a nationwide screening program on colorectal cancer mortality in Taiwan, in force since 2004, using the same design, a controlled interrupted time series analysis. They showed the program effectively reduced colorectal cancer mortality, and highlighted the importance of targeting individuals aged $70-74$ years.

Strengths and limitations

The controlled ITS approach to program evaluation controls for secular trends that might affect outcomes and therefore reduces bias that might be present in particular time-period models. ITS also has the advantage of not requiring adjustment for individual-level characteristics. Moreover, with the available data we were able to conduct stratified analyses in order to evaluate the differential impact of an intervention or the program changes on subpopulations of individuals (e.g., by age, sex) and to assess the effect of the summer season, when employees do not typically use health services. The synergistic work of IECS and ARBA officials for the health of their own employees facilitated most stages.

Competing interventions were unlikely to occur during the period evaluated. There were no changes in the instrumentation or ability to measure the outcome since the same institutions have been using the same tests for more than five years. Selection bias could have arisen, in relation to the composition of both the intervention and control groups, however neither ARBA nor IOMA candidate population changed in a significant manner over time.

Some of the Implementation issues were a) Union strikes b) Distrust by new authorities and request for additional letters of support from the Province of Buenos Aires Ministry of Health for the year 2020 phases of the project, c) High levels of bureaucracy, interference of the Argentina's national elections and changes in all levels of authorities d) The geographical distance of the peripheral ARBA offices in the province of Buenos Aires, which led to significant logistical difficulties e) Rigid ARBA regulations regarding postproduction media products. Activities planned for March 2020 e.g. the Colon Cancer Week, and Field trips were suspended due to the Covid-19 pandemic lockdown (along with the National Cancer Institute's recommendation to suspend screening activities), which led the project to a halt.

\section{Conclusions}

A multifaceted workplace-based intervention helped increase the uptake of CRC screening in public sector employees of the province of Buenos Aires, Argentina. Achieving high implementation rates requires building a healthy relationship with the partner organization, adding their values and views, and establishing agreed upon mechanisms and realistic timelines.

\section{Abbreviations}

Agencia de Recaudación, Buenos Aires (ARBA)

Biochemical Federation, Buenos Aires (FABA)

Consolidated Framework for Implementation Research (CFIR)

Colorectal cancer (CCR)

Immunochemical Fecal Occult Blood Test (iFOBT)

Interrupted time-series (ITS)

Instituto Obra Medico Asistencial (IOMA)

World Health Organization (WHO)

\section{Declarations}

\section{Ethics approval}

The present study achieved ethical approval from the Buenos Aires Province Institutional Review Board (Comité de Ética Central, CEC) under the number 8772018

\section{Consent for publication}

All authors revised the final manuscript and consented publication in its current form. 
Availability of data and material

All data generated or analysed during this study are included in this published article and its supplementary information files.

\section{Competing interests}

The authors take sole responsibility for the writing and content of the paper. All authors have no conflict interests to disclose.

\section{Funding}

This work was funded by the National Institute of Cancer Argentina, V Call for Financial Assistance to Research Projects (Disposition DI-2018-5-APN-INC \# MSYDS).

\section{Authors' contributions}

$A B, A P R$ and $L A D G$ participated to the conception/design of the review; SV and LADG to the collection/assembling of the data; SV and LG performed/supervised the analysis; LG APR and AB participated to the interpretation of the data; MC, JPA and MB participated to the application of the methodology. All authors agreed to the publication of the present work

\section{Acknowledgements}

We thank the librarian Daniel Comandé of the Institute for Clinical and Healthcare Effectiveness for his important collaboration with the bibliographic searches. We are also indebted to: Mariana Pechenik, María Celeste Ruiz, and Luján Enrique from IOMA, Gabriel Di Bastiano from FABA, and finally Soledad Balda, and Eduardo Cappello from ARBA, as well as their communications team.

\section{References}

1. International Agency for Research on Cancer (IARC). Globocan 2020. Available at: https://gco.iarc.fr/today/online-analysis-table? $\mathrm{v}=2018 \&$ mode $=$ cancer\&mode_population $=$ continents\&population $=900 \&$ populations $=900 \&$ key $=$ asr\&sex $=0 \&$ cancer $=39 \&$ type $=1 \&$ statistic $=5 \&$ prevalence $=08$ accessed Oct 2020

2. Gualdrini UA, lummato LE. Cáncer colorrectal en la Argentina: Organización, cobertura y calidad de las acciones de prevención y control. Informe final de diciembre de 2011: diagnóstico de situación de la Argentina. Propuesta del Programa de prevención y detección temprana, y acciones para su implementación Instituto Nacional del Cáncer; 2011. Available at : http://www.msal.gob.ar/images/stories/bes/graficos/0000001001cnt-2017-09-08diagnostico-situacional-cancer-colorrectal-argentina.pdf. 2011. Accessed Oct 2020.

3. Espinola N, Maceira D, Palacios A. [Cost-effectiveness of screening for colorectal cancer in Argentina.]. Acta Gastroenterol Latinoam. 2016;46(1):8-17.

4. Argentina. Instituto Nacional de Estadísticas y Censos (INDEC), Ministerio de Salud Presidencia de la Nacion. Cuarta Encuesta Nacional de Factores de Riesgo.

5. Anderson LM, Quinn TA, Glanz K, Ramirez G, Kahwati LC, Johnson DB, et al. The effectiveness of worksite nutrition and physical activity interventions for controlling employee overweight and obesity: a systematic review. Am J Prev Med. 2009;37(4):340-57.

6. Hannon PA, Vu T, Ogdon S, Fleury EM, Yette E, Wittenberg R, et al. Implementation and process evaluation of a workplace colorectal cancer screening program in eastern Washington. Health Promot Pract. 2013;14(2):220-7.

7. O'Keefe LC, Sullivan MM, McPhail A, Van Buren K, Dewberry N. Screening for Colorectal Cancer at the Worksite. Workplace Health Saf. 2018;66(4):183-90.

8. Walsh JM, Potter MB, Arora M, Gildegorin G, Terdiman J. A workplace colorectal cancer screening program in firefighters: lessons learned. Occup Med (Lond). 2014;64(4):255-8.

9. Davis MM, Freeman M, Shannon J, Coronado GD, Stange KC, Guise JM, et al. A systematic review of clinic and community intervention to increase fecal testing for colorectal cancer in rural and low-income populations in the United States - How, what and when? BMC Cancer. 2018;18(1):40.

10. Rat C, Latour C, Rousseau R, Gaultier A, Pogu C, Edwards A, et al. Interventions to increase uptake of faecal tests for colorectal cancer screening: a systematic review. Eur J Cancer Prev. 2018;27(3):227-36.

11. Programa Nacional de Prevención y Detección Temprana del CCR. Guia para la implementacion de programas de prevencion y deteccion temprana de cáncer colorectal. Available at: http://www.msal.gob.ar/images/stories/bes/graficos/0000001003cnt-2017-09-08-guia-referentes-web.pdf. Accessed 08/08/2020

12. Ramsay CR, Matowe L, Grilli R, Grimshaw JM, Thomas RE. Interrupted time series designs in health technology assessment: lessons from two systematic reviews of behavior change strategies. International journal of technology assessment in health care. 2003;19(4):613-23.

13. Community Preventive Services Task Force. Task Force Finding and Rationale Statement: Increasing Colorectal Cancer Screening: Multicomponent Interventions. Available at: https://www.thecommunityguide.org/sites/default/files/assets/Cancer-Screening-Multicomponent-Colorectal.pdf. Accessed September 10, 2018. Accessed October 2020.

14. Division of Cancer Prevention and Control. Colorectal Cancer Control Program (CRCCP). In: Centers for Disease Control and Prevention; 2018: Available at: https://www.cdc.gov/cancer/crccp/about.htm. Accessed September 10, 2018.

15. Damschroder L, Hall C, Gillon L, Reardon C, Kelley C, Sparks J, et al. The Consolidated Framework for Implementation Research (CFIR): progress to date, tools and resources, and plans for the future. Implementation Science : IS. 2015;10(Suppl 1):A12-A. 
16. Damschroder LJ, Aron DC, Keith RE, Kirsh SR, Alexander JA, Lowery JC. Fostering implementation of health services research findings into practice: a consolidated framework for advancing implementation science. Implement Sci. 2009;4:50.

17. McFall AM, Ryan JE, Hager P. Implementing a client reminder intervention for colorectal cancer screening at a health insurance worksite. Prev Chronic Dis. 2014;11:E20.

18. Rafie CL, Hauser L, Michos J, Pinsky J. Creating a Workplace Culture of Preventive Health: Process and Outcomes of the Colon Cancer-Free Zone at Virginia Cooperative Extension. J Cancer Educ. 2020;35(6):1135-40.

19. Powe BD, Ntekop E, Barron M. An Intervention Study to Increase Colorectal Cancer Knowledge and Screening Among Community Elders. Public Health Nursing. 2004;21(5):435-42.

20. Warner EL, Martel L, Ou JY, Nam GE, Carbajal-Salisbury S, Fuentes V, et al. A Workplace-Based Intervention to Improve Awareness, Knowledge, and Utilization of Breast, Cervical, and Colorectal Cancer Screenings Among Latino Service and Manual Labor Employees in Utah. J Community Health. 2019;44(2):256-64.

21. Su S-Y, Huang J-Y. Effect of nationwide screening program on colorectal cancer mortality in Taiwan: a controlled interrupted time series analysis. International Journal of Colorectal Disease. 2019;35(2):239-47.

\section{Figures}

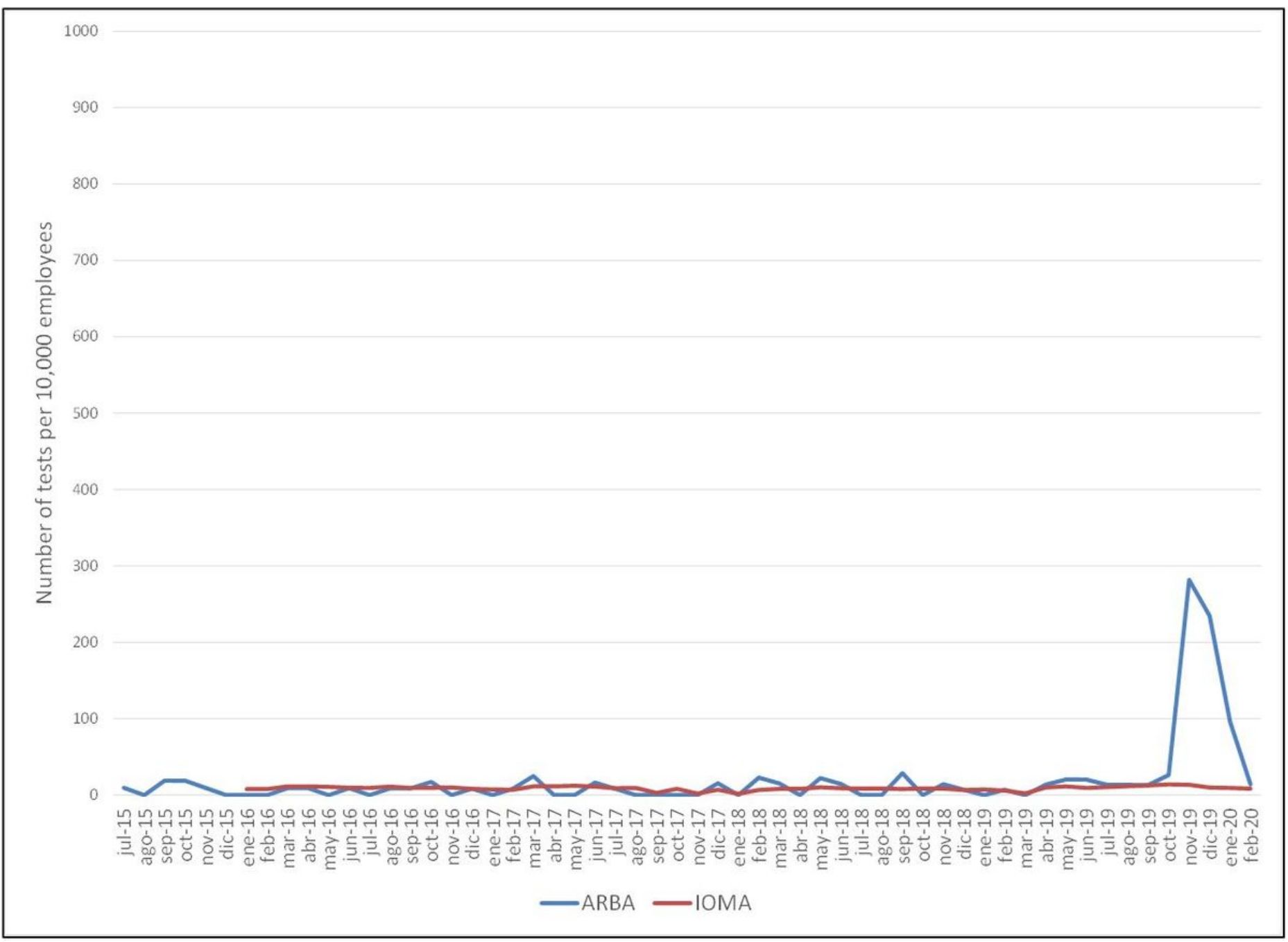

Figure 1

Number of tests done per 10,000 employees 


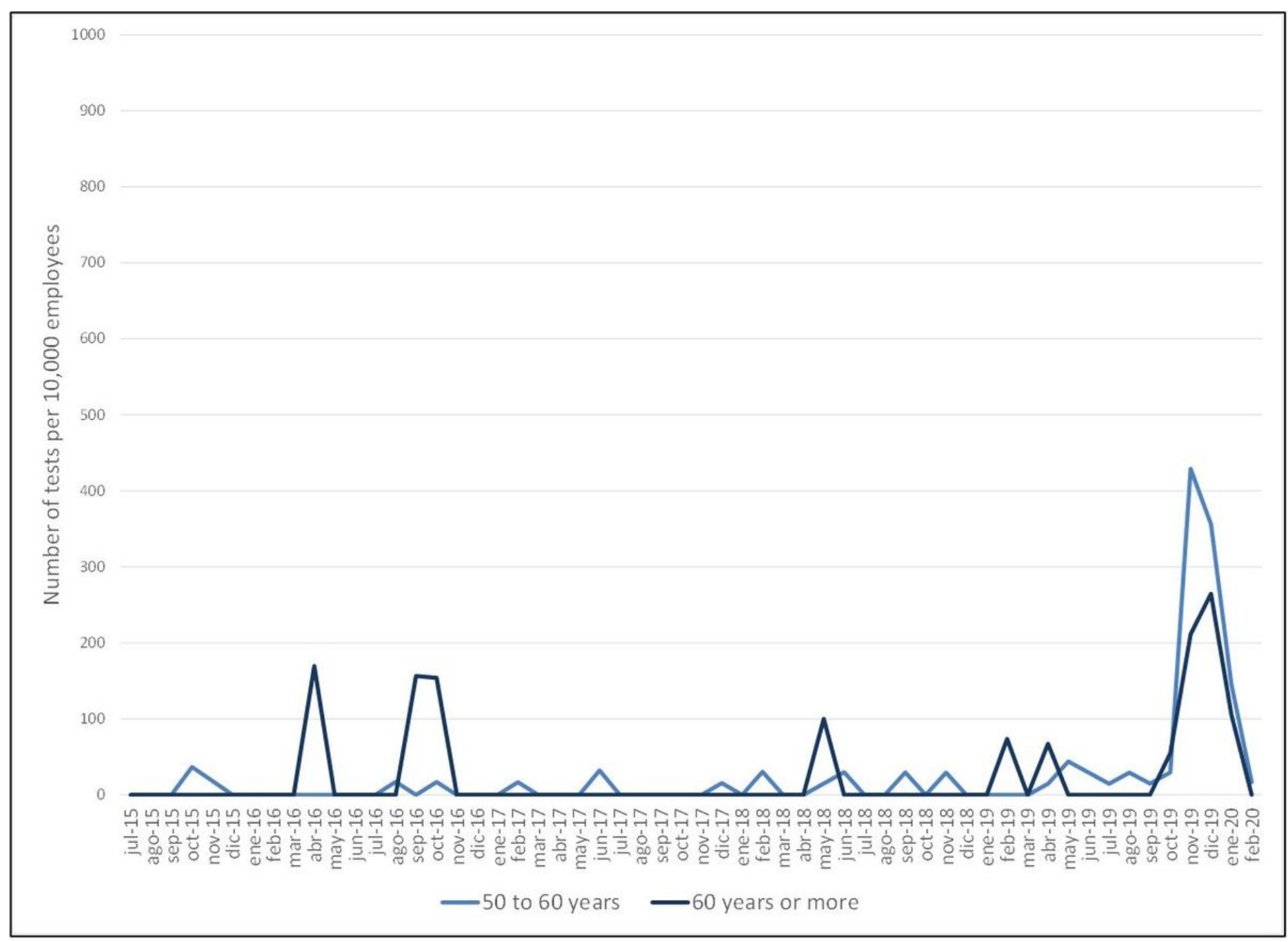

Figure 2

Number of tests done per 10,000 employees by age group in women 


\section{0}

900

800

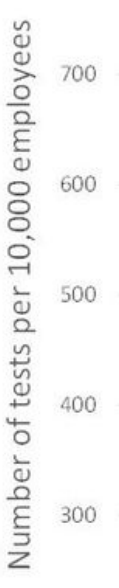

200

100

0

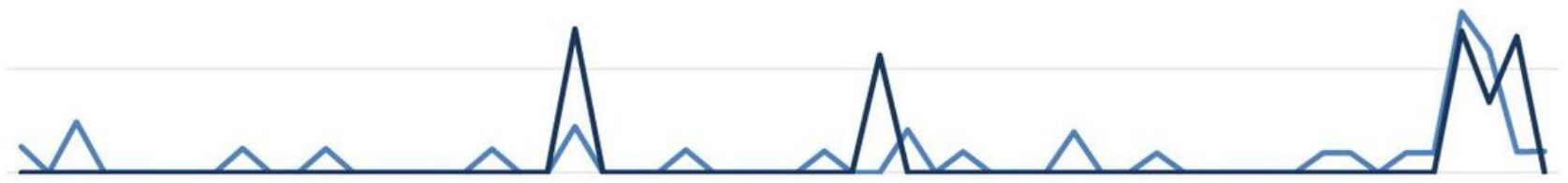

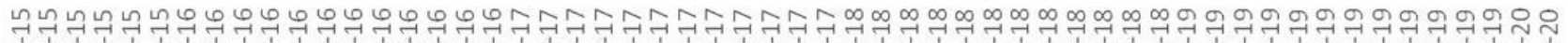

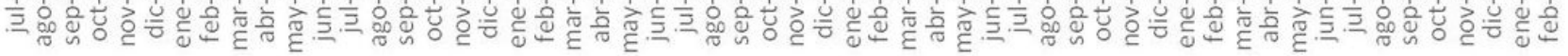

- 50 to 60 years —60 years or more

\section{Figure 3}

Number of tests done per 10,000 employees by age group in men

\section{Supplementary Files}

This is a list of supplementary files associated with this preprint. Click to download.

- APPENDIX.docX 